\title{
Tipos e volumes de diluentes para inseminação artificial intrauterina em suínos $^{1}$
}

\author{
Ana Luísa Neves Alvarenga², Luis David Solis Murgas², Márcio Gilberto Zangeronimo² \\ 1 Projeto financiado pela CAPES e pela Minitub do Brasil. \\ ${ }^{2}$ Departamento de Fisiologia e Farmacologia Veterinária da Universidade Federal de Lavras - UFLA.
}

\begin{abstract}
RESUMO - A pesquisa foi conduzida com o objetivo de avaliar diferentes tipos e volumes de diluentes por meio do desempenho reprodutivo de 72 fêmeas suínas inseminadas artificialmente. Utilizou-se o delineamento em blocos ao acaso, em esquema fatorial $3 \times 2$, com três diluentes e dois volumes inseminantes. O sêmen utilizado foi obtido de três machos de fertilidade comprovada. Os ejaculados foram diluídos em partes iguais com os diluentes comerciais A, B e C, constituindo doses com 1,5 bilhão de espermatozoides em volumes de 15 ou $30 \mathrm{~mL}$. As variáveis analisadas foram taxa de parto, índice de retorno ao estro, número total de leitões nascidos, número de leitões nascidos vivos, mumificados e natimortos e peso da leitegada ao nascimento. Não foram observadas diferenças entre as taxas de parto e as taxas de retorno ao estro. As maiores médias de número total de nascidos, nascidos vivos e peso de leitegada foram de fêmeas inseminadas com doses contendo os diluentes B e C. Não houve diferenças entre os volumes inseminantes dentro dos diluentes B e C para nenhuma das variáveis. Para o diluente A, o volume que proporcionou maior tamanho de leitegada e número de leitões nascidos vivos foi o de $15 \mathrm{~mL}$. O número de leitões natimortos e mumificados não diferiu entre os tipos e volumes de diluentes. A inseminação intrauterina de fêmeas suínas de ordem de parto 2 a 5 com doses inseminantes de $15 \mathrm{~mL}$ diluídas em diluentes de curta duração (diluentes B ou C) permite índices de desempenho reprodutivo satisfatórios.
\end{abstract}

Palavras-chave: diluentes, porcas, reprodução, volumes inseminantes

\section{Types and volumes of diluents for intrauterine artificial insemination in swine}

\begin{abstract}
The study was conducted with the objective of evaluate different types and volumes of diluents through the reproductive performance of 72 artificially inseminated sows. A randomized complete design was used in a $3 \times 2$ factorial arrangement, with three diluents and two semen volumes. The semen used was obtained from three boars of known fertility. The ejaculates were diluted in equal parts, with the commercial diluents A, B and C, constituting semen doses of 1.5 billion spermatozoids in volumes of 15 or $30 \mathrm{~mL}$. The analyzed variables were farrowing rate, indexes of return to estrus, total number of piglets born, number of piglets born alive, mummified and stillborn piglets, and litter weight at birth. Differences were not observed between the farrowing rates and indexes of return to estrus. The greatest means of total number of piglets born, piglets born alive and litter weight at birth were from females inseminated with semen doses containing diluents B and $\mathrm{C}$. There were no differences among the inseminating volumes within the diluents B and C for any of the variables. For diluent $\mathrm{A}$, the volume that provided the largest litter size and number of piglets born alive was $15 \mathrm{~mL}$. The number of stillborn and mummified piglets did not differ between the treatments. The intrauterine insemination of sows from two to five parities, with inseminating doses of $15 \mathrm{~mL}$ diluted in short term diluents (diluents B or C) give satisfactory indexes of reproductive performance.
\end{abstract}

Key Words: diluents, inseminating volumes, reproduction, sows

\section{Introdução}

A eficiência reprodutiva tem grande importância na produção de suínos e pode ser estimada pelo número de leitões desmamados por fêmea por ano. Altos índices deste parâmetro têm sido alcançados graças à utilização da técnica de inseminação artificial e de biotécnicas reprodutivas que recentemente surgiram a partir dela.

O método tradicionalmente empregado na inseminação artificial em suínos preconiza a utilização de uma pipeta, que mimetiza a extremidade do pênis do cachaço, permitindo a deposição de sêmen no canal cervical (Martinez et al., 2005). 
Uma vez que o sêmen diluído é depositado na cérvix, ele tem que percorrer todo o seu comprimento até alcançar o corpo uterino. O transporte do sêmen nesta parte do trato genital feminino depende unicamente dos movimentos peristálticos e pode ser dificultado pela barreira física, que são os anéis cervicais. Quando as contrações ascendentes não são adequadas, são produzidos refluxos seminais, pelo qual grande quantidade de material seminal se perde (Roca et al., 2006).

No final da década de 90, reiniciaram-se os estudos sobre técnicas de deposição do sêmen dentro do corpo ou corno uterino, tanto de forma cirúrgica como de forma não-cirúrgica, possibilitando a utilização de reduzido número de espermatozoides e volume, sem prejuízo do desempenho reprodutivo (Vasquez et al., 2003). A inseminação artificial cirúrgica garante a possibilidade de reduzir o número de espermatozoides com a deposição da dose inseminante próximo à junção útero-tubárica (Krueger et al., 1999; Krueger \& Rath, 2000). Entretanto, como não pode ser realizada de forma rotineira nas granjas suinícolas, técnicas que viabilizam a deposição do sêmen o mais próximo possível do local da fecundação, de forma nãocirúrgica, foram desenvolvidas para possibilitar o uso de menores volumes e número de espermatozoides (Dallanora et al., 2004). Uma delas é a inseminação artificial intrauterina.

Com a utilização dessa nova biotecnologia, serão necessárias novas condições de conservação, além de estudos sobre o melhor diluente para esta técnica (Rath, 2002).

Conhecendo o fato de que, para poder fecundar o ovócito, os espermatozoides devem capacitar-se no trato genital da fêmea, e que a capacitação está associada à fosforilação de tirosinas das proteínas espermáticas, pode-se dizer que a diluição seminal, em si, pode provocar modificações na fisiologia do espermatozoide, as quais poderiam reduzir sua capacidade fertilizante (Dubé et al., 2004). A necessidade de se desenvolverem novas tecnologias de preservação do sêmen suíno vem se destacando até os dias atuais, uma vez que ainda há uma limitação de tempo no qual o sêmen pode ser utilizado após a coleta, por isso é fundamental o desenvolvimento de diluentes capazes de permitir a sobrevivência espermática e manter elevada capacidade de fertilização (Johnson et al., 2000).

A considerável redução no volume das doses destinadas à inseminação intrauterina permitirá uma economia na quantidade de diluente consumido. Assim, esta economia poderá se voltar para a aquisição de diluentes de longa duração (Bortolozzo et al., 2005a).

Quando utilizadas doses inseminantes com baixos volumes, a relação entre o volume do ejaculado e do diluente continua muito próxima à empregada na técnica tradicional de inseminação. No entanto, o volume de ejaculado por dose reduz para valores próximos a 2 - $4 \mathrm{~mL}$. Consequentemente, o volume de plasma seminal (e outros componentes do ejaculado) estaria em quantidade absoluta inferior à da inseminação tradicional (Bortolozzo et al., 2005b).

Assim, verifica-se a necessidade de se avaliar os volumes e os tipos de diluentes a serem usados na inseminação artificial intrauterina em suínos.

\section{Material e Métodos}

O trabalho foi conduzido em uma granja comercial, com produção de suínos em ciclo completo, pertencente à Fazenda São Paulo, no município de Oliveira, Minas Gerais, entre os meses de julho e dezembro de 2007. Para realização do trabalho experimental, foram utilizadas 72 fêmeas multíparas com ordem de parto de 2 a 5 , intervalo desmame-cio de 2 a 6 dias, duração da lactação de 15 a 19 dias e tamanho médio de leitegada nos partos anteriores igual a 10 leitões. O peso das fêmeas variou de 210 a $230 \mathrm{~kg}$ para as fêmeas de ordem de parto 2, 250-260 kg para as de ordem de parto 3 e 4 , e as de ordem de parto 5 pesavam em média $270 \mathrm{~kg}$.

As fêmeas foram mantidas em gaiolas de gestação e receberam diariamente $2,40 \mathrm{~kg}$ de ração de gestação (EM=2.900 kcal/kg e 14,73\% de proteína bruta) da cobertura até o $86^{0}$ dia de gestação. Do $86^{0}$ dia até o fim da gestação, as fêmeas receberam diariamente $3,30 \mathrm{~kg}$ de ração prélactação, contendo 17,56\% de proteína bruta e 3,17 Mcal de energia metabolizável por quilo de ração.

Sete dias antes do parto, as fêmeas foram transferidas para a maternidade e submetidas a um banho completo. Durante a lactação, receberam ração de lactação à vontade, contendo $3.480 \mathrm{kcal} / \mathrm{kg}$ de energia metabolizável e 18,98\% de proteína bruta.

Como doadores de sêmen, foram utilizados três machos de fertilidade comprovada. A coleta foi realizada pelo método da mão enluvada e as doses inseminantes não foram constituídas de sêmen heterospérmico; cada fêmea foi inseminada com doses de um único macho, de forma que, para cada tratamento, foram utilizadas doses provenientes de todos os três machos. Para avaliação do ejaculado, foram considerados a motilidade, o vigor e a concentração espermáticos. A motilidade e o vigor foram avaliados em microscopia óptica com aumento de 40 vezes. A motilidade foi expressa em percentual de células móveis da amostra (0 a 100). Para o vigor, foram atribuídos valores de 1 a 5 pontos, de modo que os valores mais elevados indicaram os espermatozoides mais vigorosos. 
A concentração espermática foi obtida por contagem direta de espermatozoides utilizando a câmara de Neubauer. Cada ejaculado foi fracionado em três partes iguais e cada uma foi diluída na proporção de 1:1 utilizando-se os diluentes comerciais denominados A, B e C (Tabela 1).

Após a diluição, foram retiradas alíquotas correspondentes a 1,5 bilhão de espermatozoides de cada uma das três frações. O número total de células espermáticas de 1,5 bilhão foi obtido calculando-se, por regra de três, o volume do ejaculado a ser transferido para cada frasco, por meio da multiplicação do volume total do ejaculado diluído por 1,5 bilhão, seguida da divisão desse resultado pelo número total de espermatozoides no ejaculado.

De cada fração foram retiradas duas alíquotas e cada uma foi transferida para um frasco plástico de $100 \mathrm{~mL}$. Posteriormente, foram acrescentados os respectivos diluentes, a fim de se obterem volumes finais de 15 e $30 \mathrm{~mL}$. Portanto, para cada uma das três frações de ejaculado diluído com um diluente específico foram obtidos dois frascos com volumes diferentes, totalizando seis tratamentos (3 diluentes e 2 volumes). Foram utilizadas 12 fêmeas por tratamento. Todas as doses foram produzidas em split sample, ou seja, as doses utilizadas em ambos os tratamentos foram produzidas a partir dos mesmos ejaculados, e o sêmen foi conservado de 24 a 48 horas em temperatura de $15^{\circ} \mathrm{C}$ a $18^{\circ} \mathrm{C}$. Foi realizada uma contraprova para aferir a concentração de cada dose produzida com auxílio de um aparelho de espectrofotômetro.

Após o desmame, foi realizada a detecção do estro, duas vezes por dia (manhã e tarde), pelo reflexo de tolerância ao homem na presença do macho. Posteriormente ao início do estro, as fêmeas foram distribuídas aleatoriamente em gaiolas individuais de gestação e foram inseminadas pela

Tabela 1 - Composição dos diluentes comerciais A, B e C

\begin{tabular}{lccc}
\hline Produto & $\mathrm{A}^{1}$ & $\mathrm{~B}^{2}$ & $\mathrm{C}^{2}$ \\
\hline Glicose (g) & 66,25 & 79,90 & 89,20 \\
Citrato de sódio (g) & 11,00 & 12,71 & 3,05 \\
Bicarbonato de sódio (g) $_{\text {EDTA }^{3} \text { (g) }}$ & 13,50 & 2,65 & 4,20 \\
Tris $^{4}$ (g) & 6,50 & 2,65 & 3,05 \\
Cloreto de potássio (g) $_{\text {Sulfato de Gentamicina (g) }}$ & 2,00 & - & - \\
Água deionizada (l) & 0,75 & 1,59 & - \\
Osmolaridade (mOsm) & 1,00 & 0,59 & 0.50 \\
pH & 309 & 330 & 1,00 \\
\hline
\end{tabular}

Valores para cada $100 \mathrm{~g}$ de diluente.

${ }^{1}$ Diluente considerado de longa duração (período de conservação superior a três dias);

${ }^{2}$ Diluentes considerados de curta duração (período de conservação por até três dias);

3 EDTA: ácido etilenodiaminotetraacético;

${ }^{4}$ TRIS: tris(hidroximetil)aminometano. técnica de inseminação artificial intrauterina (IAIU), de modo que, para cada tratamento, foram utilizadas fêmeas de todas as ordens de parto entre 2 e 5 . Para esta técnica utilizou-se uma pipeta de inseminação artificial descartável (tubo de polipropileno com esponja de poliuretano) e um cateter semirrígido de polipropileno, com $3 \mathrm{~mm}$ de diâmetro externo e dois milímetros de diâmetro interno. O cateter deslizava internamente à pipeta, estendendo-se $20 \mathrm{~cm}$ além das pregas cervicais, alcançando a região da bifurcação dos cornos, ou mesmo um dos cornos uterinos, permitindo a deposição intrauterina da dose inseminante. As inseminações foram realizadas por um único inseminador, de modo que cada fêmea recebeu duas inseminações por cio, com um total de 1,5 bilhão de espermatozoides cada. As inseminações foram realizadas na presença do macho: a primeira 24 horas após as fêmeas apresentarem sintomas característicos do cio, e a segunda, 24 horas depois da primeira.

O diagnóstico de retorno ao estro foi efetuado do $18^{\mathrm{o}}$ ao 23ํㅡ dia após a inseminação, pelo teste de reflexo de tolerância ao homem na presença do macho. Entre 25 e 30 dias após a inseminação artificial, foi realizado o diagnóstico de gestação, em que todas as fêmeas submetidas à IAIU foram examinadas por ultrassonografia transcutânea em tempo real, com transdutor setorial de $5 \mathrm{MHz}$.

As variáveis analisadas foram taxa de parto (número de matrizes que pariram em relação ao número de matrizes que foram inseminadas), índice de retorno ao cio (porcentagem das fêmeas que retornaram ao cio após terem sido inseminadas), número total de leitões nascidos, número de leitões nascidos vivos, mumificados e natimortos, e peso da leitegada ao nascimento.

Foi adotado um delineamento em blocos ao acaso, em esquema fatorial $3 \times 2$ (três diluentes e dois volumes inseminantes). Os blocos foram constituídos pela ordem de parição e pelo macho doador do ejaculado, totalizando 12 repetições com um animal por parcela experimental.

Os parâmetros número total de leitões nascidos, número de leitões nascidos vivos e peso da leitegada ao nascimento foram submetidos à análise de variância e as médias comparadas entre si pelo teste Tukey.

As variáveis taxa de parto, taxa de retorno ao estro e número de leitões mumificados e natimortos foram submetidas à análise não-paramétrica, visto que os dados não atingiram a normalidade, mesmo após a transformação. Neste caso, as médias foram comparadas pelo teste de Kruskal-Wallis quando houve significância ao teste quiquadrado $(\mathrm{P}<0,05)$. 
Todas as análises foram realizadas utilizando-se o Sistema de Análise Estatística e Genética - SAEG (UFV, 1993).

\section{Resultados e Discussão}

As taxas de parto e os índices de retorno ao cio das fêmeas inseminadas não diferiram $(\mathrm{P}>0,05)$ entre os diluentes e volumes utilizados (Tabela 2). Em concordância com o trabalho de Dallanora et al. (2004), a deposição intrauterina de 1,5 bilhão de espermatozoides permitiu a formação eficiente do reservatório espermático na junção úterotubárica e adequada fecundação. Os valores encontrados neste estudo quando utilizados os volumes de $30 \mathrm{~mL}$ para o diluente B (91,70\%) e $15 \mathrm{~mL}$ para os diluentes A e C (91,70\%) também foram próximos aos descritos no trabalho de Dallanora et al. (2004), no qual as doses destinadas à inseminação intrauterina das matrizes suínas foram diluídas em $60 \mathrm{~mL}$ de BTS e resultaram em taxas de parto de $92,80 \%$.

O percentual de fêmeas paridas variou de $75,00 \%$ a 91,70\%. A maior frequência de retorno ao cio foi de $25,00 \%$ para fêmeas inseminadas com sêmen diluído em C com doses de $30 \mathrm{~mL}$. Vasconcelos et al. (2001), ao compararem diluentes de longa duração (Zorlesco-modificado e BTZOR) ao BTS, utilizaram doses inseminantes de 5 bilhões de espermatozoides em $100 \mathrm{~mL}$ de BTS destinados à inseminação tradicional e encontraram taxas de retorno ao cio superiores às deste trabalho $(32,10 \%)$. Segundo Jainudeen \& Hafez (2004), 25,00\% a 40,00\% dos embriões são naturalmente perdidos nas espécies domésticas, entre a época de penetração do óvulo pelo espermatozoide e o final da implantação.

Scheid (1991), ao testar os diluentes Kiew, BTS (diluentes de curta duração) e o Reading (diluente de longa duração) em volumes de $100 \mathrm{~mL}$, encontrou taxas de parto que não diferiram significativamente: 87,10\% para Kiew; 91,70\% para BTS; e 89,80\% para Reading. O mesmo ocorreu neste trabalho, onde diferenças entre os diluentes não foram encontradas para esta variável.
Entre as doses que continham $15 \mathrm{~mL}$, aquelas que foram diluídas em $\mathrm{A}$ e $\mathrm{C}$ apresentaram taxas de parto superiores. Por outro lado, as doses diluídas em $\mathrm{B}$ apresentaram maiores taxas de parto quando continham $30 \mathrm{~mL}$.

Segundo Reis (1997), a taxa de diluição do sêmen é um fator que interfere no período de preservação e viabilidade dos espermatozoides e, consequentemente, nos resultados de inseminação artificial. Behan \& Watson (2004) compararam a eficiência reprodutiva de matrizes suínas inseminadas com 1,5 bilhão de espermatozoides, diluídos em 25, 50 e $75 \mathrm{~mL}$ de diluente Safecell Plus. Diferenças significativas foram encontradas para as taxas de parto entre as fêmeas inseminadas com $50 \mathrm{~mL}$ (91,50\%) e $75 \mathrm{~mL}(91,90 \%)$ versus aquelas inseminadas com $25 \mathrm{~mL}$ (63,40\%). O volume de $30 \mathrm{~mL}$, tecnicamente o mais próximo ao de $25 \mathrm{~mL}$ utilizado no trabalho de Behan \& Watson (2004) apresentou, em média, taxa de parto mais alta que os valores encontrados por esses autores. Essa diferença pode ter sido em virtude dos diferentes diluentes utilizados em ambos os trabalhos.

Embora as taxas de parto e os índices de retorno ao cio não tenham apresentado diferenças significativas entre tipos e volumes dos diluentes, o número total de leitões nascidos e o número de leitões nascidos vivos diferiram entre os grupos (Tabela 3). Entre as doses de $15 \mathrm{~mL}$, não houve diferença entre os diluentes utilizados. As fêmeas inseminadas com doses de $30 \mathrm{~mL}$ apresentaram maior tamanho de leitegada e número de leitões nascidos vivos quando o sêmen foi diluído em $\mathrm{B}$ e $\mathrm{C}(\mathrm{P}<0,05)$. Estes dados contradizem os descritos por Ratto \& Jokinen (1990), que, ao compararem diluidores de curta duração aos de longa duração, não observaram diferenças na fertilidade ou na prolificidade das fêmeas suínas inseminadas com doses com três bilhões de espermatozoides em 100 mL.

Neste estudo, os diluentes de curta duração apresentaram maiores médias de leitões nascidos vivos em relação ao diluente de longa duração $(\mathrm{P}<0,05)$ para o volume de $30 \mathrm{~mL}$. Vasconcelos et al. (2001), no entanto, observaram que o diluente de longa duração (Zorlesco-modificado) apresentou maiores médias de número total de leitões nascidos $(11,89)$ e de número de leitões nascidos vivos $(10,37)$ em relação aos

Tabela 2 - Taxa de parto e índice de retorno ao estro das fêmeas inseminadas pela técnica de inseminação intrauterina

\begin{tabular}{|c|c|c|c|c|}
\hline \multirow[t]{2}{*}{ Diluente } & \multicolumn{2}{|c|}{ Taxa de parto (\%) } & \multicolumn{2}{|c|}{ Taxa de retorno ao cio (\%) } \\
\hline & $15 \mathrm{~mL}$ & $30 \mathrm{~mL}$ & $15 \mathrm{~mL}$ & $30 \mathrm{~mL}$ \\
\hline A & $91,70(11 / 12)$ & $83,30(10 / 12)$ & $8,30(1 / 12)$ & $16,70(2 / 12)$ \\
\hline B & $83,30(10 / 12)$ & $91,70(11 / 12)$ & $16,70(2 / 12)$ & $8,30(1 / 12)$ \\
\hline $\mathrm{C}$ & $91,70(11 / 12)$ & $75,00(9 / 12)$ & $8,30(1 / 12)$ & $25,00(3 / 12)$ \\
\hline$P=0,97$ & & & & \\
\hline
\end{tabular}

*Não-significativo pelo teste de qui-quadrado $(\mathrm{P}>0,05)$. 
outros diluentes utilizados (8,97 e 7,55 para BTS e 9,18 e 7,33 para BTZOR, respectivamente). Provavelmente, as maiores médias obtidas com o diluente Zorlesco-modificado foram consequência da presença do soro fetal bovino existente em sua composição, o que deve ter propiciado melhores condições aos seus espermatozoides, em decorrência de suas propriedades antiaglutinantes e antitóxicas em relação aos outros diluentes (BTZOR e BTS) e até mesmo em relação ao diluente de longa duração A utilizado neste estudo.

Os valores encontrados neste estudo com os diluentes de curta duração (B e C) foram superiores aos obtidos por Vasconcelos et al. (2001) com o diluente BTS. Essas diferenças talvez estejam relacionadas às metodologias utilizadas e comprovam as possíveis influências do número de espermatozoides (1,5 bilhão vs 5 bilhões), do volume inseminante (15 ou $30 \mathrm{~mL}$ vs $100 \mathrm{~mL}$ ) e da técnica de inseminação (intrauterina vs tradicional) sobre a prolificidade das fêmeas. Segundo Baker et al. (1968), o tempo de conservação, o volume e o número de espermatozoides por dose inseminante influenciam as respostas reprodutivas. Matthijs et al. (2003) realizaram um estudo com o objetivo de avaliar a influência do volume inseminante no recrutamento de neutrófilos e fagocitose das células espermáticas utilizando doses inseminantes com 2,4 bilhões de espermatozoides diluídos em $20 \mathrm{~mL}$ ou $80 \mathrm{~mL}$. Esses autores observaram que a perda de espermatozoides por refluxo pode ser reduzida e que o número de espermatozoides não fagocitados retidos no útero pode ser melhorado através de redução do volume inseminante. As porcas inseminadas com o volume de $20 \mathrm{~mL}$ tiveram um número significativa- mente mais alto de espermatozoides não fagocitados no útero. Quatro horas depois de inseminação, o número de espermatozoides no oviduto das porcas inseminadas com $20 \mathrm{~mL}$, não era significativamente mais alto que o número de espermatozoides no oviduto nas fêmeas inseminadas com $80 \mathrm{~mL}$, mas a população espermática significativamente maior no útero poderia ser importante para manter adequada população espermática no oviduto por um período mais longo depois de inseminação, o que afetaria diretamente a fertilidade da fêmea.

No trabalho de Dallanora et al. (2004), no qual as doses destinadas à inseminação intrauterina das matrizes suínas continham 1,5 bilhão de espermatozoides em $60 \mathrm{~mL}$ de BTS, o número total de leitões nascidos foi de 11,6, enquanto neste experimento, foram encontrados para os diluentes de curta duração (B e C, respectivamente) valores menores (10,8 a 10,9 para os volumes de $15 \mathrm{~mL}$ ) e maiores (12,1 a 13,0 para os de $30 \mathrm{~mL}$ ) que aquele.

Não houve diferenças entre os volumes dentro dos diluentes $\mathrm{B}$ e $\mathrm{C}(\mathrm{P}>0,05)$. Para o diluente $\mathrm{A}$, o volume que proporcionou maior tamanho de leitegada $(\mathrm{P}<0,05)$ foi de $15 \mathrm{~mL}$ (Figura 1).

O número de leitões natimortos e mumificados não diferiu $(\mathrm{P}>0,05)$ entre os diluentes e volumes utilizados (Tabela 4). Os valores estão dentro dos limites preconizados tanto para natimortos (de 0,67 a 1 leitão por leitegada) quanto para mumificados (de 0,11 a 0,58 leitão por leitegada) para ambas as técnicas (tradicional e intrauterina) utilizadas na deposição do sêmen (Wentz et al., 2006).

O número de natimortos observados neste estudo foi inferior aos encontrados na literatura. Toniolli \& Mesquita

Tabela 3 - Número total de leitões nascidos, de leitões nascidos vivos e peso da leitegada ao nascer das fêmeas inseminadas

\begin{tabular}{|c|c|c|c|c|}
\hline \multirow[t]{2}{*}{ Diluente } & \multicolumn{2}{|c|}{ Volume (mL) } & \multirow[t]{2}{*}{ Média } & \multirow[t]{2}{*}{ CV $(\%)$} \\
\hline & 15 & 30 & & \\
\hline \multicolumn{5}{|c|}{ Total de leitões nascidos } \\
\hline A & $12,50 \pm 0,78 a$ & $9,50 \pm 0,78 \mathrm{Bb}$ & $11,00 \pm 0,55$ & \\
\hline B & $10,80 \pm 0,78$ & $12,10 \pm 0,78 \mathrm{AB}$ & $11,40 \pm 0,55$ & \\
\hline $\mathrm{C}$ & $10,90 \pm 0,78$ & $13,00 \pm 0,78 \mathrm{~A}$ & $12,00 \pm 0,55$ & \\
\hline Média & $11,40 \pm 0,45$ & $11,50 \pm 0,45$ & & 23,55 \\
\hline \multicolumn{5}{|c|}{ Leitões nascidos vivos } \\
\hline A & $12,0 \pm 0,69 a$ & $8,8 \pm 0,69 \mathrm{Bb}$ & $10,4 \pm 0,49$ & \\
\hline B & $10,1 \pm 0,69$ & $10,7 \pm 0,69 \mathrm{AB}$ & $10,4 \pm 0,49$ & \\
\hline $\mathrm{C}$ & $10,5 \pm 0,69$ & $12,3 \pm 0,69 \mathrm{~A}$ & $11,4 \pm 0,49$ & \\
\hline Média & $10,8 \pm 0,40$ & $10,6 \pm 0,40$ & & 22,42 \\
\hline \multicolumn{5}{|c|}{ Peso da leitegada ao nascer $(\mathrm{kg})$} \\
\hline A & $17,71 \pm 1,05$ & $14,90 \pm 1,05 \mathrm{~B}$ & $16,29 \pm 0,74$ & \\
\hline B & $16,27 \pm 1,05$ & $18,50 \pm 1,05 \mathrm{~A}$ & $17,40 \pm 0,74$ & \\
\hline $\mathrm{C}$ & $16,24 \pm 1,05$ & $18,00 \pm 1,05 \mathrm{AB}$ & $17,12 \pm 0,74$ & 21,56 \\
\hline Média & $16,74 \pm 0,60$ & $17,13 \pm 0,60$ & & \\
\hline
\end{tabular}

\footnotetext{
${ }^{1}$ Médias na linha/coluna seguidas de mesma letra minúscula/maiúscula não diferem ( $\left.\mathrm{P}>0,05\right)$ pelo teste Tukey.
} 


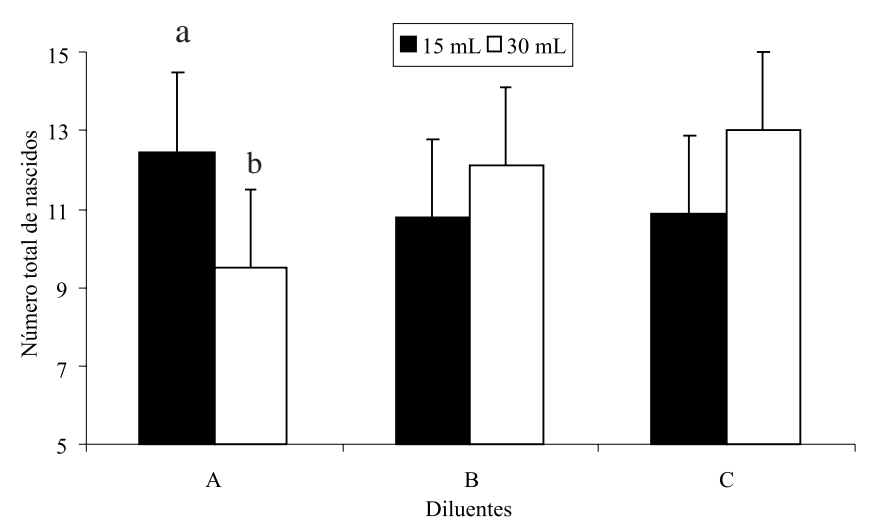

a,b letras diferentes dentro de um mesmo diluente implicam diferenças estatísticas pelo teste de Tukey $(\mathrm{P}<0,05)$.

Figura 1 - Médias do número total de leitões nascidos de fêmeas inseminadas com sêmen suíno diluído nos diluentes $\mathrm{A}$, B e C constituindo doses de 15 e $30 \mathrm{~mL}$.

(1990), utilizando doses de 3 bilhões de espermatozoides em $100 \mathrm{~mL}$ de BTS, encontraram 6,20\% de leitões natimortos. Esse valor, apesar de dentro dos valores aceitáveis (4,80 a 9,00\%), foi bem alto.

A distribuição da natimortalidade entre fêmeas suínas segue um caráter normal, com a maioria das fêmeas frequentemente parindo um pequeno número de natimortos, enquanto poucas matrizes apresentam taxas elevadas. Entre os fatores envolvidos associados à presença de natimortos, podem ser citados: ordem de parto, tamanho da leitegada, duração do parto, escore corporal visual, auxílio ao parto (toque vaginal), peso da leitegada, presença de mumificados na leitegada, intervalo entre os nascimentos dos leitões, peso ao nascer e fatores estressantes, além das causas infecciosas (Wentz et al., 2006).
A extensão das perdas fetais que culminam em mumificados é de 0,50\% a 1,50\%, em média, por leitegada. Wentz et al. (2006) sugeriram a existência de duas causas principais prováveis para a ocorrência de mumificação fetal: a falta de espaço uterino, com descolamento precoce de placenta, e doenças de caráter progressivo no útero, capazes de causar a morte de vários fetos na mesma leitegada. Aqueles autores também relatam que a mortalidade fetal em suínos, principalmente a mumificação, tem aumentado, em razão do aumento na taxa de ovulação e da provável limitação da capacidade uterina. O tamanho da leitegada também pode ser considerado fator de risco para mumificados, quanto maior a leitegada, maior a taxa de leitões mumificados.

O peso médio da leitegada ao nascimento não diferiu $(\mathrm{P}>0,05)$ entre os diluentes utilizados quando as doses foram de $15 \mathrm{~mL}$. Dentro de um mesmo diluente, as médias encontradas foram similares $(\mathrm{P}>0,05)$, independentemente do volume do diluente.

Em concordância com as variáveis número total de leitões nascidos e número de leitões nascidos vivos, as maiores médias de peso de leitegada ao nascimento foram provenientes de leitegadas de fêmeas inseminadas com doses diluídas em B e C, seguidas pelas leitegadas de fêmeas inseminadas com doses diluídas em $A(P<0,05)$.

Resultados inferiores aos deste estudo foram obtidos por Dimitrov et al. (2007), que, ao testarem doses inseminantes de 1,5 bilhão de espermatozoides em $50 \mathrm{~mL}$ de BTS destinadas à inseminação intrauterina, encontraram peso médio de leitegada de 16,08 kg. Essa diferença pode ser atribuída ao fato de que, além dos volumes utilizados terem sido diferentes, esses autores utilizaram fêmeas com intervalo desmame-cio superior a seis dias, o que diminui o tamanho e o peso de leitegada.

Tabela 4 - Médias e erros-padrão do número de leitões natimortos e mumificados presentes nas leitegadas das fêmeas inseminadas

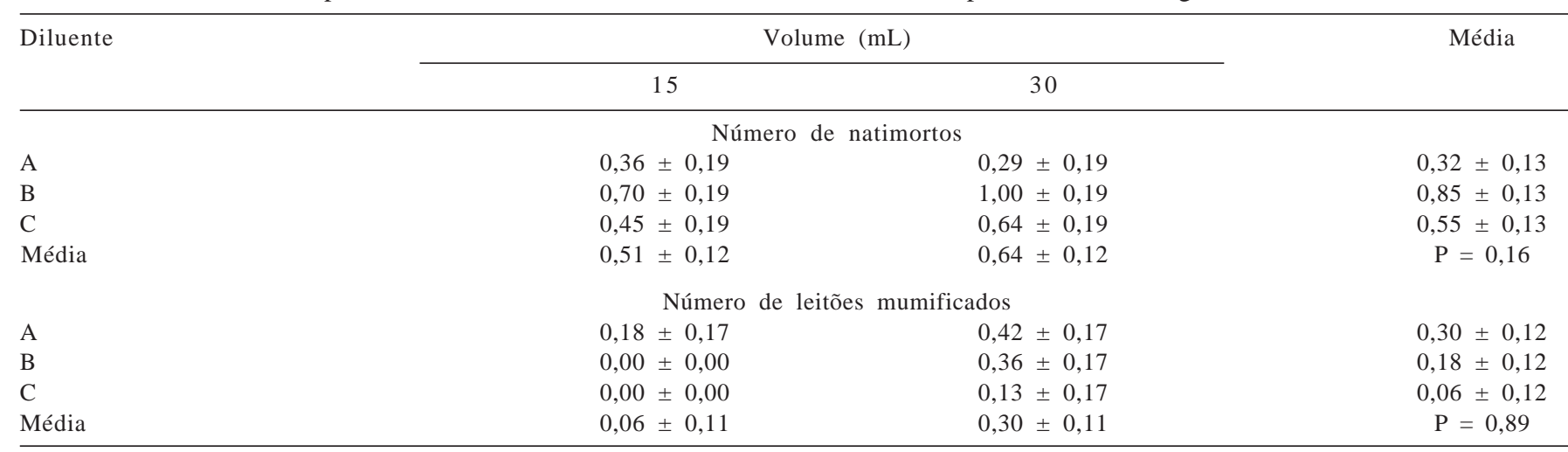

*Não-significativo ao teste de qui-quadrado $(\mathrm{P}>0,05)$. 


\section{Conclusões}

A inseminação intrauterina de fêmeas suínas de ordem de parto 2 a 5 com doses inseminantes de $15 \mathrm{~mL}$ diluídas em diluentes de curta duração (B ou C) permite obter índices de desempenho reprodutivo satisfatórios.

\section{Literatura Citada}

BAKER, R.D.; DZIUK, P.J.; NORTON, H.W. Effect of volume of semen, number of sperm and drugs on transport of sperm in artificially inseminated gilts. Journal of Animal Science, v.27, p.88-93, 1968.

BEHAN, J.R.; WATSON, P.F. A commercially based field trial to investigate trans-cervical insemination at reduce volume and sperm concentration in sows. In: INTERNATIONAL CONGRESS ON ANIMAL REPRODUCTION, 15., 2004, Porto Seguro. Proceedings... Porto Seguro: Colégio Brasileiro de Reprodução Animal, 2004. p.573.

BORTOLOZZO, F.P.; BERNARDI, M.L.; WENTZ, I. Perspectiva do emprego da inseminação artificial intrauterina em suínos. In: CONGRESSO DA ASSOCIAÇÃO BRASILEIRA DE VETERINÁRIOS ESPECIALISTAS EM SUÍNOS, 12., 2005, Fortaleza. Anais... Fortaleza: ABRAVES, 2005a. v.1. p.36-47.

BORTOLOZZO, F.P.; WENTZ, I.; DALLANORA, D. Situação atual da inseminação artificial em suínos. Acta Scientiae Veterinariae, v.33, n.1, p.17-32, 2005 b.

DALLANORA, D.; MEZALIRA, A.; KATZER, L.H. et al. Desempenho reprodutivo de fêmeas suínas inseminadas pela técnica intrauterina ou tradicional. Pesquisa Agropecuária Brasileira, v.39, n.8, p.815-819, 2004.

DIMITROV, F.; DIMITROV, M.; DIMITROV, S. et al. [2007]. Inseminación post-cervical en hembras multíparas con concentración reducida de espermatozoides por dosis: resultados de campo en Bulgaria. Disponível em: <http://64.233.169.104search?q= cache:uGg4tAqwO3wJ:www.avancesentecnologiaporcina.com/ contenidos/insene $7 . h t m+$ inseminacion+post+cervical+gil\&hl= pt-BR\&ct=clnk\&cd=4>. Acesso em: 25/4/2007.

DUBÉ, C.; BEAULIEU, M.; REYES-MORENO, C. et al. Boar sperm storage capacity of BTS and Androhep Plus: viability, motility, capacitation, and thyrosine phosphorylation. Theriogenology, v.62, p.874-886, 2004.

JAINUDEEN, M.R.; HAFEZ, E.S.E. Falha reprodutiva em fêmeas. In: HAFEZ, E.S.E. (Ed.) Reprodução animal. São Paulo: Manole, 2004. cap. 17, p.261-278.

JOHNSON, L.A.; WEITZE, K.F.; FISER, P. et al. Storage of boar semen. Animal Reproduction Science, v.62, n.1/3, p.143-172, 2000.
KRUEGER, C.; RATH, D. Intrauterine insemination in sows with reduced sperm number. Reproduction Fertility and Development, v.12, p.113-117, 2000.

KRUEGER, C.; RATH, D.; JOHNSON, L.A. Low dose insemination in synchronized gilts. Theriogenology, v.52, p.1363-1373, 1999.

MARTINEZ, E.A.; VAZQUEZ, J.M.; ROCA, J. et al. An update on reproductive technologies with potencial short-term application in pig production. Reproduction in Domestic Animals, v.40, n.4, p.300-309, 2005.

MATTHiJS, A.; ENGEL, B.; WOELDERS, H. Neutrophil recruitment and phagocytosis of boar spermatozoa after artificial insemination of sows, and the effect of inseminate volume, sperm dose and specific additivies in the extender. Reproduction, v.125, p.357-367, 2003.

RATH, D. Low dose insemination in the sow - a review. Reproduction in Domestic Animals, v.37, p.201-205, 2002

RATTO, J.; JOKINEN, L. Reports about number of swine inseminations and farrowing results in Finland 1989, comparison between two diluents EDTA and MR-A. Reproduction in Domestic Animals, v.1, p.365-368, 1990 (suppl.).

REIS, F.T. Colheita, avaliação e manipulação do ejaculado de suínos. Revista Brasileira de Reprodução Animal, v.21, n.3, p.22-29, 1997.

ROCA, J.; VAZQUEZ, J.M.; GIL, M.A. et al. Challenges in pig artificial insemination. Reproduction Domestic Animal, v.42, n.2, p.43-53, 2006.

SCHEID, I.R. Inseminação artificial em suínos: diluentes para a conservação do sêmen no estado líquido. Concórdia: EMBRAPA/CNPSA, 1991. 5p. (Comunicado Técnico, 12).

TONIOLLI, R.; MESQUITA, D.S.M. Fertilidade de porcas inseminadas com sêmen diluído em água de coco estabilizada e com BTS. Revista Brasileira de Reprodução Animal, v.14, n.4, p.249-254, 1990.

UNIVERSIDADE FEDERAL DE VIÇOSA - UFV. Sistemas para análises estatísticas - SAEG. Versão 5.0. Viçosa, MG: Fundação Arthur Bernardes, 1993.

VASCONCELOS, A.M.M.A.; MORAES, G.V.; RIGOLON, L.P. et al. Efeito de sêmen resfriado e diluído em Beltsville Thawing Solution, Zorlesco-Modificado e BTZOR no desempenho reprodutivo de fêmeas suínas inseminadas. Revista Brasileira de Zootecnia, v.30, n.2, p.402-408, 2001.

VAZQUEZ, J.M.; MARTINEZ, E.A.; PARRILLA, I. et al. Birth of piglets after deep intrauterine insemination with flow cytometrically sorted boar spermatozoa. Theriogenology, v.59, n.7, p.1605-1614, 2003.

WENTZ, I.; CYPRIANO, C.R.; VARGAS, A.J. et al. Fatores de risco para leitões natimortos e mumificados. In: CONGRESSO LATINO-AMERICANO DE SUINOCULTURA, 3., 2006, Foz do Iguaçu. Anais... Foz do Iguaçu: Embrapa 2006. p.271-288. 